\title{
F-Hydra Index for Evaluating Groundwater Vulnerability in Data Scarce Regions
}

\author{
Amos T. Kabo-bah (Corresponding author) \\ Department of Energy and Environmental Engineering, University of Energy and \\ Natural Resources, Sunyani, Ghana \\ Tel: 233-543-859-721_E-mail: amos.kabobah@uenr.edu.gh
}

\section{Gloria Appiah-Sefah}

Department of Environmental Engineering, Hohai University, No 1 Xikang Road 210098, Nanjing, Jiangsu, P.R. China

Tel: 86-159-519-51344Ｅ-mail: gee88m@gmail.com

G. K. Anornu

Department of Civil Engineering, KNUST, Kumasi, Ghana

Tel: 233-244-882-912Ｅ-mail: anoprof@hotmail.com

Kyereh Boateng

Faculty of Renewable Natural Resources, KNUST, Kumasi, Ghana

E-mail: kyerehb@gmail.com

Received: December 30, 2013 Accepted: February 19, 2013 Published: March 26, 2014

doi:10.5296/jee.v5i1.5361 URL: http://dx.doi.org/10.5296/jee.v5i1.5361

\begin{abstract}
Groundwater resources continue to be an important source of water supply for communities in developing countries. However, rapid population growth and urbanization, challenges the potential of groundwater to serve and meet the needs of growing populace. Various techniques have been developed over the last decade to assess groundwater vulnerability due
\end{abstract}


changes in climate and prevailing natural environmental conditions. The difficulty in most of these methods has been intensive data requirements. This paper developed an innovative method called f-hydra index using three key parameters - flow accumulation (derived from Digital Elevation Model), landcover map and hydraulic conductivity. The results of the index were successfully evaluated with widely used index - DRASTIC (for the Densu River Basin of Ghana, West Africa. The comparison of f-hydra to DRASTIC shows highly correlated areas in mapping vulnerable regions in the study area. The f-hydra index proves a noble way to assess groundwater vulnerability to pollution in data scarce regions. Authors envisaged the testing of the model in many other regions to ascertain it's replicability globally.

Keywords: DRASTIC, Digital Elevation Model (DEM), Landcover, Hydraulic conductivity 


\section{Introduction}

Over the years, water has proven to be a very important human resource and thus vital for the sustenance of life. In many economies, water is mostly used for domestic, industrial, recreational, agricultural as well as cultural purposes. With the dwindling amount of available surface water due to population growth, agriculture, urbanization and industrialization, a higher percentage of the populace has resorted to the use of groundwater as supplement and has become the major source of water for most activities. Although most people have thought of groundwater as being clean due its location, climate change and industrialization among other factors (Villholth, 2010, Audretsch \& Thurik, 2000) have increasingly made them susceptible to pollution especially in developing countries (Anornu et al., 2012). Several studies have outlined the health as well as environmental risks that are associated with this kind of pollution (Lee et al., 2010; Törnqvist et al., 2011; Karim 2000; Emmanuel et al., 2009). This means that, groundwater has increasingly become vulnerable but this has however not stopped the rising demand for it.

Groundwater contamination can be defined as the pollution of groundwater by substances mainly of human origin leading to the degradation of the matrix (Fried, 1975). These contaminants are usually from urban areas, agricultural and industrial activities, waste disposal sites as well as saline or polluted water that get into the groundwater due to over-exploitation. Oil spills and landfill leakages can also pollute the groundwater aquifer. Some of these substances get soaked within the groundwater whiles those that do not dissolve get pooled there and serve as long-term sources of contamination (USEPA, 1996). Whereas surface water contamination is easier to identify, monitor and remediate, groundwater contamination is difficult to. The geology of an area and anthropogenic activities being undertaken within an area, mostly defines how susceptible the aquifers would be to contamination (Anornu et al., 2012; Lobo-Ferreira 1999; Foster and Chilton, 2003). Other factors such as the groundwater flow velocity and the hydrodynamic dispersion characteristics of the aquifer determine its susceptibility to pollution (Seiler et al., 1999; Glaser, 1998).

Groundwater vulnerability maps employ the use of Geographical Information System (GIS) to identify aquifers that may be vulnerable to contamination and to help in decision-making. Some of the methods employed in groundwater vulnerability maps include EPIK (Doerfliger and Zwahlen, 1998), "German method", ISI (Civita and De Regibus, 1995), GOD (Foster, 1987), SINTACTS (Civita, 1994), PI (Goldscheider et al., 2000), DRASTIC (Aller et al., 1987) and the AVI method (Van Stempvoort et al., 1992). Almost all of these methods tend to focus on the vertical movement of contaminants within a matrix, ignoring the horizontal movement. Gogu et al., (2003) suggests that the best way of assessing aquifer vulnerability is to take into consideration an appropriate scale, data on the geology, hydrogeology, hydrology, soil, topography, climate as well as land-use. Among the aforementioned methods, the DRASTIC method has gained popularity in most research works typically because it is user-friendly, accepted widely based on GIS approach and makes use of all the parameters mentioned above (Panagopoulos et al., 2006; Yang et al., 2012, Merchant 1994). However, a limitation to its use is the high number of parameters that are employed which some are 
difficult to obtain or measure. Furthermore, in most developing countries as in Ghana, groundwater data are scarce and difficult to access. According to Van Stempvoort et al. (1992), the selection of the various parameters used in DRASTIC are usually complex and the assigning of weights to the various parameters are arbitrary, reducing the authenticity of the method in some cases. However, since the method seems to be the commonest, further improvements ought to be done to it.

The Densu River Basin located in Ghana is one of the main river basins in the country (Fig 1). It serves the domestic, agricultural as well as industrial needs of most people living within the basin and other parts of the country. The Weija reservoir located in this basin is the second largest in the country and serves as an important source of drinking water to about 2.5 million people (Asante et al., 2005; GB\&F, 2011). Due to rapid population growth, poor sanitation conditions, the use of dangerous chemicals for fishing as well as industrialization in communities situated in the basin, the quality of both the surface and groundwater from the river have been threatened. The scarcity of groundwater historical data and the cost associated with acquiring it calls for the need to develop an aquifer vulnerability index that would employ the use of less and readily available data.

Therefore, the objective of the research was to assess the vulnerability of the River Densu Basin to groundwater pollution using the newly developed f-hydra index. The results obtained from the f-hydra index were evaluated with the widely used DRASTIC method to ascertain its reliability. 


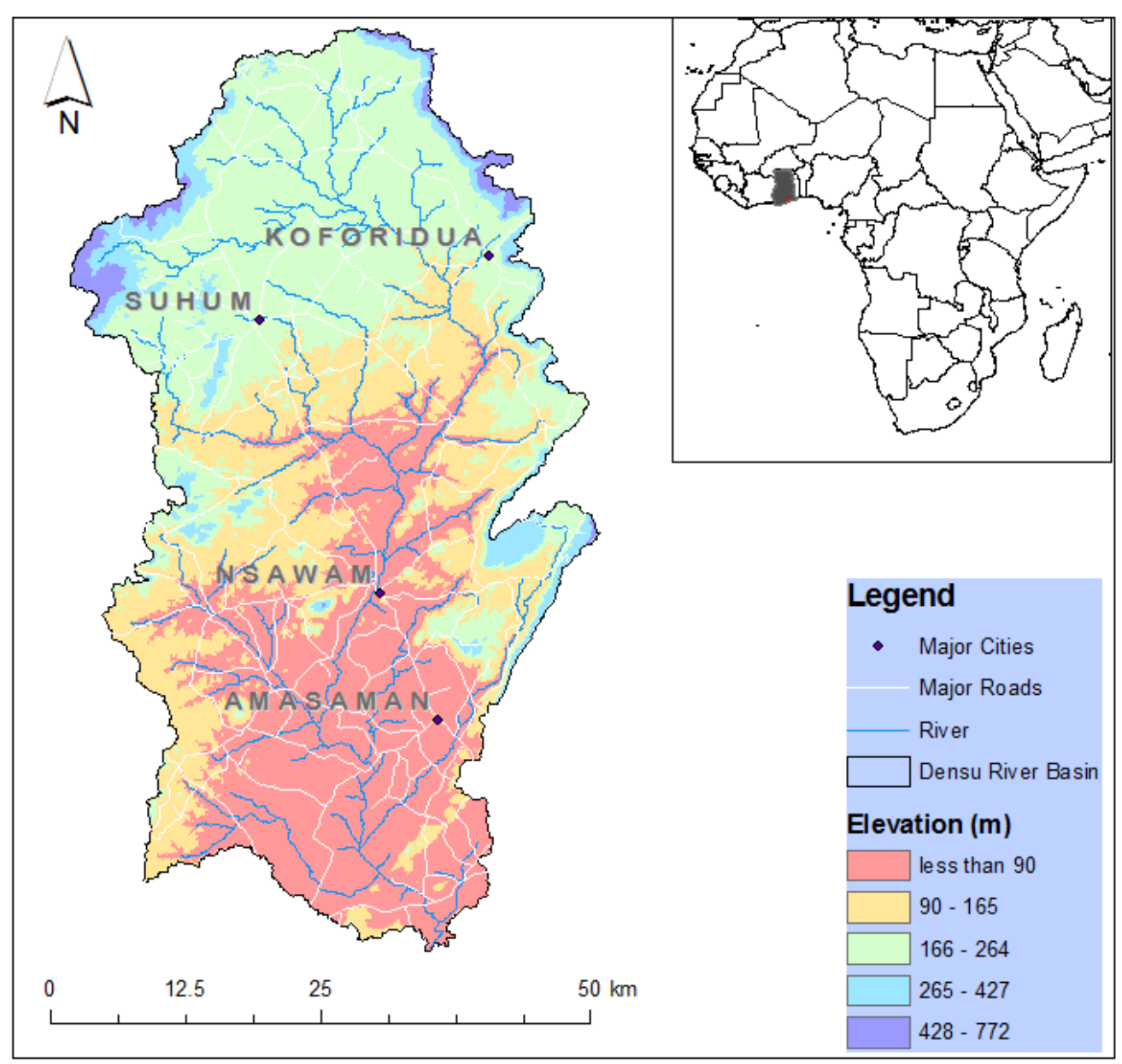

Figure 1. Densu River Basin

\section{Materials and Methods}

\subsection{DRASTIC Basic Approach}

The DRASTIC vulnerability index map was designed based on the method outlined by Aller et al., (1987). Data sources, parameters considered and weightings are as indicated in Table 1.

DRASTICIndex $=D_{R} D_{W}+R_{R} R_{W}+A_{R} A_{W}+S_{R} S_{W}+T_{R} T_{W}+I_{R} I_{W}+C_{R} C_{W}$

Where $\mathrm{R}$, rating and $\mathrm{W}$, weight

$$
K=\frac{4 W^{2 R}}{H^{2}-(H-d)^{2}} \quad \text { (Luo et al, 2011) }
$$

Where 
$\mathrm{K}$, is the hydraulic conductivity

$\mathrm{R}$, is recharge rate

$\mathrm{d}$, is the valley depth

$\mathrm{H}$, is the aquifer thickness

$\mathrm{W}$, is the length of effective groundwater drainage.

\subsection{F-Hydra Index}

The f-hydra index was developed with three parameters namely, flow accumulation $(f a)$, hydraulic conductivity and landcover. Flow accumulation is an operation within the Integrated Land Water Information System (ILWIS) software that performs a cumulative count of the number of the pixels that naturally drain into an outlet. In principle, the $f a$ is used to describe the drainage pattern of a terrain. In order to derive the $f a$ map, a flow direction $(f d)$ is first created. This operation determines the natural flow direction of a pixel based on the D-8 flow algorithm. In ILWIS, a digital elevation model (DEM) is used for the computation of the $f d$. In this paper, the $f d$ was derived from SRTM DEM. The derived $f d$ map was automatically used to derive the $f a$ for the study area. The $f a$ was considered as a critical input for information about the various "ponding zones" within the study area. Ponding zones refer to the areas susceptible to high potential availability of groundwater recharge from precipitation. This implies in principle, a highly concentrated ponded zone, means a higher contribution to groundwater potential recharge. Figure 2 (1-4) illustrates the procedure for deriving the flow accumulation using a DEM. 


\section{MInstitute ${ }^{\text {Mnk }}$}

1. Computing Flow Direction(FD) from a DEM using the Steepest Slope Approach

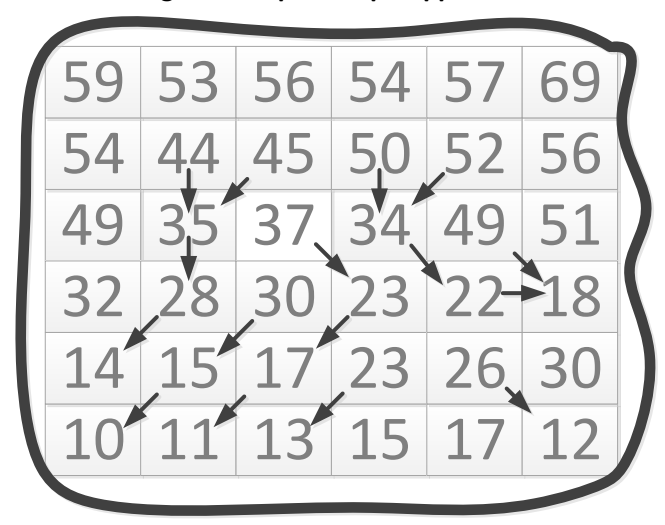

2. Output flow direction map

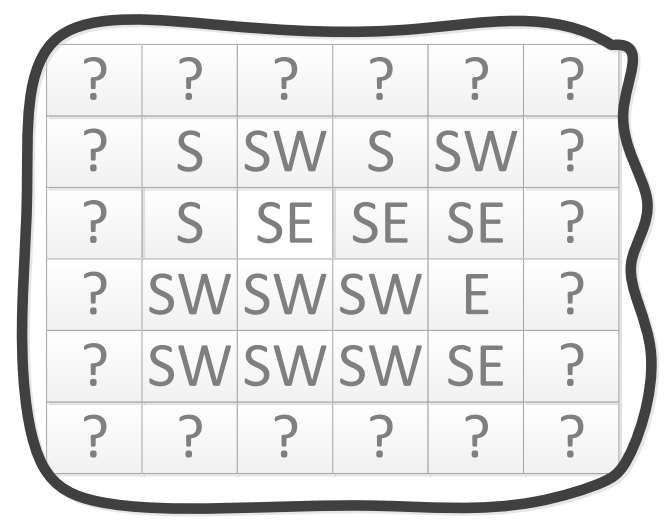

4. Flow Accumulation Map

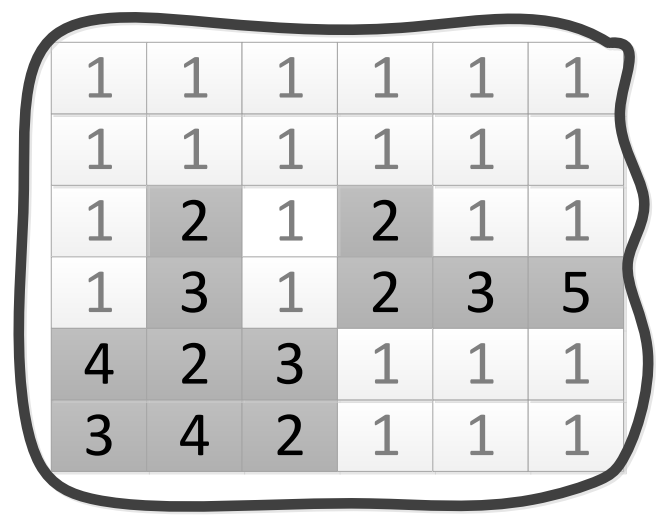

3. Computing flow accumulation using FD map

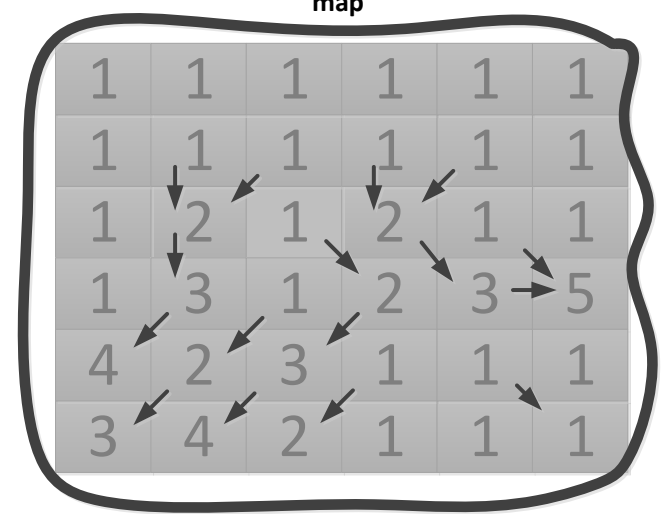

Figure 2. Procedure for deriving the flow accumulation map

Hydraulic conductivity $(\boldsymbol{K})$ on the other hand, is a function of the recharge rate, valley depth, aquifer thickness and the length of effective groundwater drainage and as such, a ' $\boldsymbol{K}$ ' map is a representation of the aforementioned parameters (Anornu et al, 2012). $\boldsymbol{K}$, is a fundamental requirement in the determination of the quantum of the groundwater drag.

Landcover map is also a function of geology, soil type, formation type and slope. The flow accumulation, the hydraulic conductivity and landcover maps were then processed using ILWIS. Weights were then assigned to each of the parameters based on Table 1 and Table 2 . The weighting for the parameters were determined using practical relevance of each of the parameters to contribute to groundwater vulnerability.

The f-hydra index was thus developed based on Equation 3. 


$$
f-\text { hydra }=f_{a} * W_{f a}+h y d_{c o n d} * W_{h y d}+l_{c} W_{l_{c}}
$$

Where

$f_{a} \quad$ Flow accumulation map

$l_{c} \quad$ Land cover map

hyd $_{\text {Cond }} \quad$ Hydraulic conductivity

$W_{f_{a}} \quad$ Weighting of flow accumulation

$W_{\text {hyd }} \quad$ Weighting based on property of spatial hydraulic conductivity

$W_{l_{c}} \quad$ Weighting based on property of landcover characteristics

\subsection{Data Sources}

Table 1. Data sources used for DRASTIC indices

\begin{tabular}{|c|c|c|}
\hline Parameter & Data type & $\begin{array}{l}\text { DRASTIC } \\
\text { weights }\end{array}$ \\
\hline Depth of water & Pumping test data & 5 \\
\hline Net recharge & 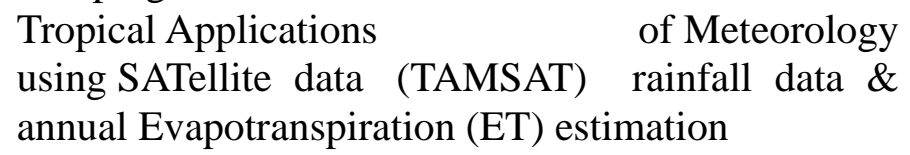 & 4 \\
\hline Aquifer media & Geological map, Ghana & 3 \\
\hline Soil media & Soil map, Ghana & 2 \\
\hline Slope & $\begin{array}{l}\text { Shuttle Radar Topography Mission (SRTM) 90m } \\
\text { DEM }\end{array}$ & 1 \\
\hline $\begin{array}{l}\text { Impact of vadose } \\
\text { zone }\end{array}$ & Well logs, geological map, Ghana & 5 \\
\hline $\begin{array}{l}\text { Hydraulic } \\
\text { conductivity }\end{array}$ & $\begin{array}{l}\text { Algorithm developed by (Luo and Pederson, 2012, } \\
\text { Luo et al., 2011), see equation (2) }\end{array}$ & 3 \\
\hline
\end{tabular}


Table 2. Data sources used for f-hydra indices

\begin{tabular}{llc}
\hline Parameter & Data type & Weights (\%) \\
\hline Flow Accumulation & Derived from 90m SRTM DEM & 30 \\
Hydraulic conductivity & Algorithm developed by [1, 2], see equation (2) & 40 \\
Landcover map & http://www.iscgm.org & 30 \\
\hline
\end{tabular}

\section{Results and Discussion}

The weighted parameters - flow accumulation, landcover and hydraulic conductivity are provided in Figure 2. Using Equation 3, the resultant vulnerability map was computed based on the weighted maps. The results of the final vulnerability map for the study areas using both DRASTIC and f-hydra methods are provided in Figure 3. The two methods yielded similar results (See Table 3). Although the DRASTIC has been identified as a method that is easy to be interpret (Panagopoulos et al, 2006), the method makes use of several parameters which are often difficult to obtain or measure. For example, it is always very difficult to obtain pumping test data from drilled wells. Pumping test data is vital in the case of DRASTIC method to determine the Depth of Water and Impact of the Vadose zone. Another important indicator required by the DRASTIC is net recharge and aquifer media. For small catchments, obtaining such information is often impractical. The basic purpose of groundwater vulnerability indices is to identify areas in the study area that are potentially risky in terms of the aquifer resource availability and usage.

The f-hydra method relies on core factors that are vital for providing information about groundwater vulnerability. The flow accumulation map that is generated from the DEM take into account the natural drainage pattern as well as the possible percolation and ponding areas in the study area. The landcover map shows the various activities on the land surface that may have impact on the groundwater resources. These maps combined with the hydraulic conductivities of the area (i.e. hydraulic conductivity is a function of soil type, soil viscosity, geology and slope), provides an optimum solution for assessing the vulnerability state of the groundwater in the study area. From the f-hydra, $f a$ map was used as an important measure because it shows the drainage pattern of the area and indicates in this particular case, an innovative parameter for determining groundwater vulnerability. The accumulation of water within the basin is relatively low as shown in the flow accumulation map (Figure 2). According to the f-hydra index, about $68.49 \%$ of the total area of Densu is highly vulnerable to pollution with the remaining $29.59 \%$ and $1.92 \%$ having moderate and low susceptibility respectively. The DRASTIC index for the same area estimated about $71.52 \%$ of the area was highly vulnerable whiles moderate and low susceptibility percentages were around $26.71 \%$ and $1.77 \%$ respectively. These differences in percentages can be argued off as very small and may be used as estimation for the other. Statistically, the percentage of pixels assigned to the various classes in the DRASTIC index was not so different from that assigned to the f-hydra index (Table 3). Therefore, the index developed proved to be viable for vulnerability mapping 
within the Densu River basin. Both indices showed that, more than $50 \%$ of the aquifers within the basin will be highly susceptible to contaminant pollution once they occur. Although the f-hydra method has been simplified for vulnerability assessment in data scarce regions, the results obtained is an indication that the index can be used successfully in these areas because the results obtained did not differ greatly from that of the DRASTIC (i.e. the $\mathrm{R}^{2}$ of the mapped areas of DRASTIC and f-hydra has a high value of 0.9957).

The f-hydra as in the case of DRASTIC has its technical limitations as it does not consider the horizontal flow of contaminants and variability in the hydraulic conductivity of aquifers at different soil layers. In this case, it may also not predict pollution in the subsurface to a greater degree since movement of pollutants within the subsurface areas were not considered.

Notwithstanding these limitations, the f-hydra provides an innovative and faster reference guide for assessing groundwater vulnerability, especially in regions where it is not possible to obtain all the 7 parameters required by DRASTIC. However, more vigorous test of the index is required for small and large watersheds for more reliable estimates.

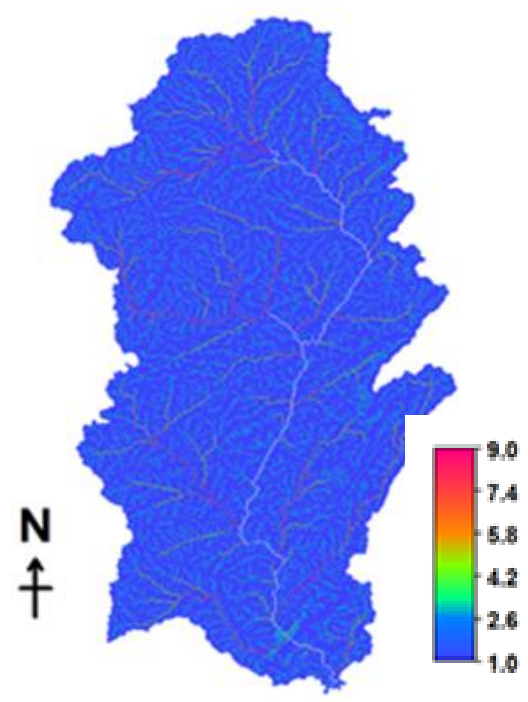

Flow Accumulation

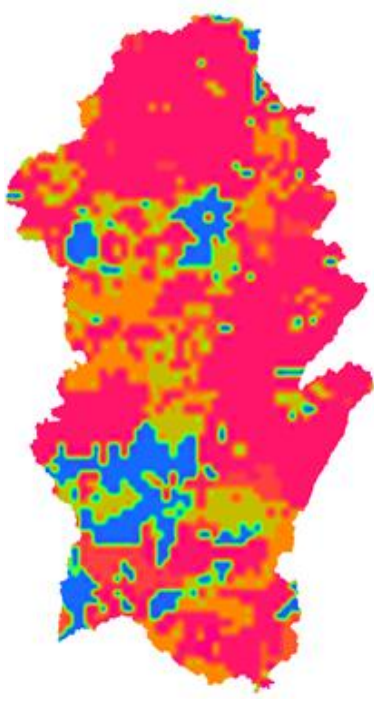

Landcover

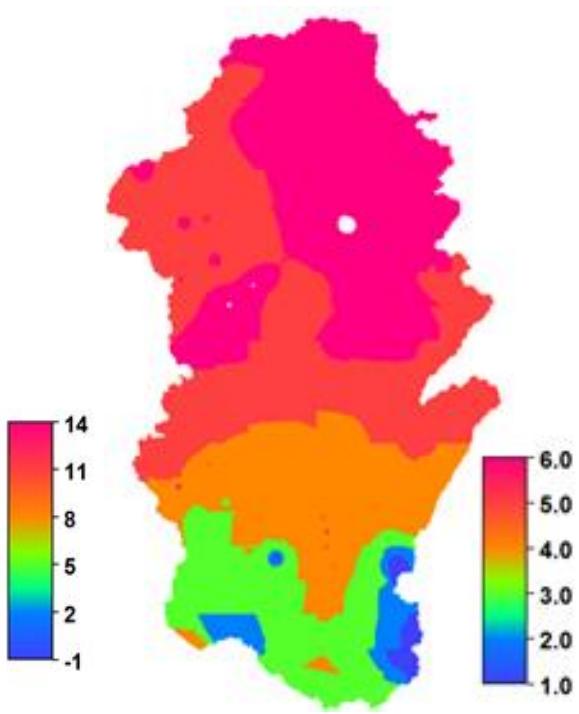

Hydraulic Conductivity

Figure 2. Assigned weights to parameters for f-hydra 

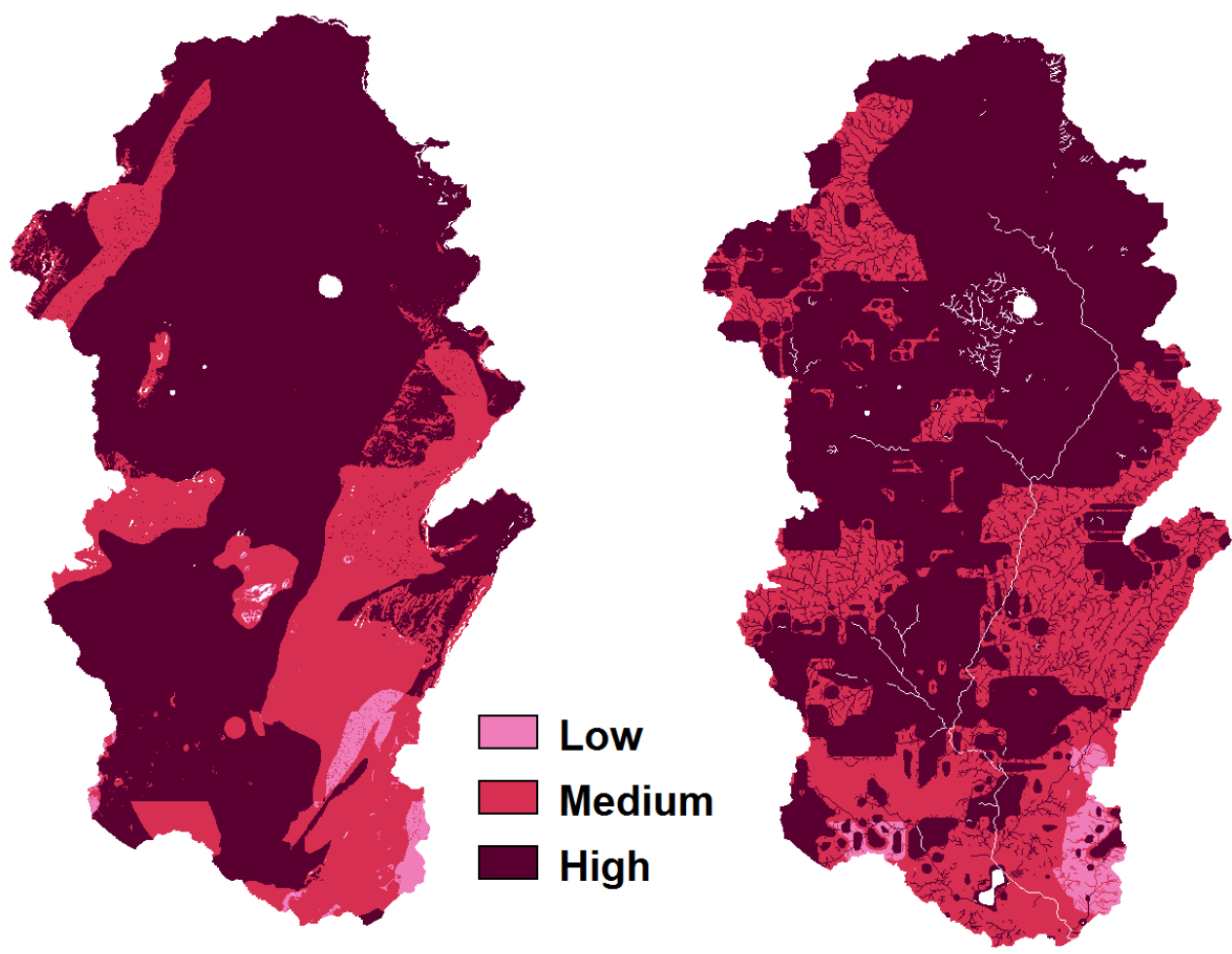

Figure 3. Aquifer vulnerability of the Densu River basin using DRASTIC (left) and f-hydra (right)

Table 3. DRASTIC and f-hydra classification matrix

\begin{tabular}{|c|c|c|}
\hline Classification & DRASTIC, \% & Area Coverage \\
\hline Low & 1.77 & 1.92 \\
\hline Medium & 26.71 & 29.59 \\
\hline High & 71.52 & 68.49 \\
\hline
\end{tabular}

\section{Conclusion}

Groundwater vulnerability mapping is important to provide information to decision makers towards the planning, prioritising and designing monitoring programmes. There are many methods to assess groundwater vulnerability. The most popular among them is the DRASTIC method. The challenge with this method however is the data requirements which makes it unsuitable for data scarce regions. In this paper, the f-hydra was developed and proved measurable to the capabilities of the DRASTIC. The mapped areas of low, moderate and high vulnerability show close correlation between the newly developed method, f-hydra and DRASTIC. Therefore, the f-hydra index thus proves an innovative and good index to help managers in data scarce regions to conduct vulnerability mapping. The index is in its early stages of development and might not readily give an estimate of the actual vulnerability of aquifers in different regions. However, the authors believe that it provides a good estimate of 
the susceptibility of aquifers to pollution and thus can help authorities in decision making and planning especially in regions that may find it difficult to obtain all the inputs required by other methods. Future improvement of the index is thus envisaged and recommended.

\section{References}

Aller L., T. Bennett, J. Lehr, R.J. Petty, \& G. Hackett (1987). DRASTIC: A Standardized System for Evaluating Ground Water Pollution Potential Using Hydrogeologic Settings. NWW AIEPA Series, U.S. Environmental Protection Agency, Ada, Okla.

Anokye, N. A., \& Gupta, J. (2011). Reconciling IWRM and water delivery in Ghana-The potential and the challenges. Physics and Chemistry of the Earth, Parts A/B/C. http://dx.doi.org/10.1016/j.pce.2011.06.010.

Anornu, G., Kabo-Bah, A., \& Kortatsi, B. (2012). Comparability studies of high and low resolution digital elevation models for watershed delineation in the tropics: Case of Densu River Basin of Ghana. International Journal of Cooperative Studies, 1(1), 9-14.

Asante K.A., Quarcoopome T., \& Amevenku F.Y.K. (2005). Water Quality of the Weija Reservoir after 28 years of Impoundment. West African Journal of Applied Ecology, 13, 171-180. http://dx.doi.org/10.4314/wajae.v13i1.40588

Audretsch, D. B., \& Thurik, A. R. (2000). Capitalism and democracy in the 21st Century: from the managed to the entrepreneurial economy. Journal of Evolutionary Economics, 10, $1-2,17-34$.

Bagtzoglou, A. C, Dougherty, D. E., \& Tompson, A.F.B. (1992). Application of particle methods to reliable identification of groundwater pollution sources. Water resources management, 6, 15-23.

Civita, M. (1994). La carta della vulnerabilitadegli acquiferi all'inquinamiento. Pitagora, Bologna.

Civita, M., \& De Regibus, C. (1995). Sperimentazione di alcune metodologie per la valutazione della vulnerabilità degli aquiferi (Development of a methodology for the assessment of aquifer vulnerability). Q GeolApplPitagora, 3(1995), 63-71.

Doerfliger, N., \& Zwahlen, F. (1998). Groundwater Vulnerability Mapping in Karstic Regions (EPIK), Practical Guide. Swiss Agency for the Environment. Forests and Landscape (SAEFL). Berne, 56.

Emmanuel E., Pierre M. G., \& Perrodin Y. (2009). Groundwater contamination by microbiological and chemical substances released from hospital wastewater: health risk assessment for drinking water consumers. Environment international, 35, 718-726. http://dx.doi.org/10.1016/j.envint.2009.01.011

Foster S.S.D. (1987). Fundamental concepts in aquifer vulnerability, pollution risk and protection strategy. In Duijvenbooden W, \& Waegeningh HG (Eds), Vulnerability of soil and groundwater to pollutants. TNO committee on hydrological research. The Hague, Proc Info. 
38:69-86.

Foster S. S. D., \& Chilton P. J. (2003). Groundwater: the processed and global significance of aquifer degradation. Phil Trans R Soc land B. 358, 1957-1972

Fried, J. J. (1975). Groundwater pollution: In Developments in Science, Chow VT (ed). Elsevier scientific. Amsterdam, The Netherlands. Pp 1.

Ghana Business and Finance (GB\&F). (2011). Dam in danger. http://www.ghanabizmedia.com/ghanabizmedia/january-2012-environment/484-dam-in-dang er.html.

Gogu R.C., Hallet V, \& Dassargues A. (2003). Comparison of aquifer vulnerability assessment techniques. Application to the Neblon river basin (Belgium). Environmentl geology, 44(8), 881-892.

Goldscheider N., Klute M, Sturm S., \& Hotzl H. (2000). The PI method-a GIS-based approach to mapping groundwater vulnerability with special consideration on karst aquifers. ZAngewGeol, 46(3), 157-166.

Karim M. (2000). Arsenic in groundwater and health problems in Bangladesh. Water Resources, 34(1), 304-310. http://dx.doi.org/10.1016/S0043-1354 (99)00128-1

Lee L.J.H., Chen C.H., Chang Y.Y., Liou S.H., \& Wang J.D. (2010). An estimation of the health impact of groundwater pollution caused by dumping of chlorinated solvents. Science of the total environment, 408, 1271-1275.

Lobo-Ferreira, J. P. (1999). The European Union experience on groundwater vulnerability assessment and mapping." COASTIN A Coastal Policy Research Newsletter, 1, 8-10.

Luo, W., \& Pederson, D. T. (2012). Hydraulic conductivity of the High Plains Aquifer re-evaluated using surface drainage patterns. Geophysical Research Letters, 39, L02402.

Luo, W., Grudzinski, B. P., \& Pederson, D. T. (2011). Estimating hydraulic conductivity for the Martian subsurface based on drainage patterns - A case study in the Mare Tyrrhenum Quadrangle. Geomorphology, $\quad$ 125, 414-420. http://dx.doi.org/10.1016/j.geomorph.2010.10.018

Merchant, J. W. (1994). GIS-based groundwater pollution hazard assessment: a critical review of the DRASTIC model. Photogrammetric engineering and remote sensing, 60, 1117-1128.

Miller D.W. (1984). Sources of groundwater pollution. 10 EPA L. 17.

Panagopoulos, G.P., Antonakos A.K., \& Lambrakis N.J. (2006). Optimization of the DRASTIC method for groundwater vulnerability assessment via the use of simple statistical methods and GIS. Hydrogeology journal, 14, 894-911.

Seiler R.L., Zaugg S.D., Thomas J. M., \& Howcroft D.L. (1999).Caffeine and pharmaceuticals as indicators of waste water contamination in wells. Ground Water, 37, 405 
-410 .

Törnqvist R., Jarsjö J., \& Karimov B. (2011). Health risks from large-scale water pollution: Trends in Central Asia. Environmental International, 37, 435-442

UESPA (2012). Surface and groundwater. [Online] Available: http://www.epa.gov/agriculture/tsur.html.

US Environmental Protection Agency (1996). Environmental indicators of water quality in the United States: Washington, DC office of water, EPA 841-R-96-002, EPA, Washington DC.

Van Stempvoort D., Ewert L., \& Wassenaar L. (1992). Aquifer vulnerability index: A GIScompatible a method for groundwater vulnerability mapping. Scientific hydrology/ Sciences hydrologiques, 18(1).

Vidyasagar, D. (2007). Global minute: water and health-walking for water and water wars. Journal of perinatology, 27(1), 56-58.

Villholth, K. G., \& Lorraine D. R. (2010). Groundwater Resources and Management Challenges in Sri Lanka-an Overview.Water resources management, 24(8), 1489-1513.

Yang, G., Jiang, Y., \& Li, Y. (2012). Review on urban groundwater vulnerability assessment by using DRASTIC Model. Ground water, 01.

\section{Copyright Disclaimer}

Copyright reserved by the author(s).

This article is an open-access article distributed under the terms and conditions of the Creative Commons Attribution license (http://creativecommons.org/licenses/by/3.0/). 